\title{
Role of work hardening characteristics of matrix alloys in the strengthening of metal matrix composites
}

\author{
K T KASHYAP*, C RAMACHANDRA, C DUTTA and B CHATTERJI \\ Central Materials and Process Laboratory, Hindustan Aeronautics Limited, Bangalore 560 017, India
}

MS received 16 September 1999; revised 6 January 2000

\begin{abstract}
The strengthening of particulate reinforced metal-matrix composites is associated with a high dislocation density in the matrix due to the difference in coefficient of thermal expansion between the reinforcement and the matrix. While this is valid, the role of work hardening characteristics of the matrix alloys in strengthening of these composites is addressed in the present paper. It is found that commercial purity aluminium which has the lowest work hardening rate exhibits the highest strength increment. This effect is due to increased prismatic punching of dislocations. This relationship of decreasing work hardening rate associated with increasing prismatic punching of dislocations in the order 7075, 2014, 7010, 2024, 6061 and commercial purity aluminium leading to increased strength increments is noted.
\end{abstract}

Keywords. Metal matrix composites; strengthening; work hardening rate; dislocation density.

\section{Introduction}

While in continuous fibre composites, strengthening is associated with load transfer by the matrix to the fibre (Clyne and Withers 1993), in whisker and particulate reinforced composites, it is associated with the high dislocation density in the matrix (Arsenault and Shi 1986; Arsenault et al 1991). Arsenault and Fisher (1983) proposed that the increased strength observed in $\mathrm{SiC} / \mathrm{Al}$ composites could be accounted for by the high dislocation density in aluminium due to the large difference in the coefficient of thermal expansion (CTE) between the reinforcement and the matrix. Vogelsang et al (1986) verified this experimentally in situ HVEM studies of SiC/Al composite where they found a high dislocation density after cooling the composite from 773 to $300 \mathrm{~K}$. Arsenault and Shi (1986) proposed a simple model to predict prismatic punching of dislocation at the reinforcement/matrix interface due to CTE mismatch. However, the role of matrix behaviour in $\mathrm{SiC} / \mathrm{Al}$ composites has not received much attention. It is observed (Nair et al 1985) that the average increase in UTS of the composite relative to the matrix appears to be larger for the lower yield strength alloys. Marcus (1984) found that the lower yield strength Alalloy matrices show less interface failure between $\mathrm{SiC}$ and Al-alloy matrix, which can partly account for the variation in strengthening in various $\mathrm{Al}$ alloys.

Webster (1982) also found that the increment in yield strength and ultimate tensile strength increased as the

\footnotetext{
*Author for correspondence
}

yield strength of the matrix decreased. He suggested that the $\mathrm{SiC} / \mathrm{Al}$ interface bonding could be an important factor to explain the composite yield behaviour.

It is therefore clear that the tensile behaviour of SiC/Al alloy composites as a function of different aluminium alloys matrices is not well understood. In the present work, an attempt is made to rationalize the role of different aluminium alloy matrices in governing the strength of $\mathrm{SiC} / \mathrm{Al}$ metal matrix composites.

\section{Experimental}

Different aluminium alloys were selected as potential candidate materials for MMCs. They are AA6061, AA2024, AA7010, AA2014, AA7075 and commercial purity aluminium. The nominal compositions of these alloys are shown in table 1 . These alloys were fully recrystallized at a temperature of $400^{\circ} \mathrm{C}$ for $3 \mathrm{~h}$. Tensile test samples with $5 \mathrm{~mm}$ gauge diameter and $25 \mathrm{~mm}$ gauge length were made and engineering stress-strain curves were obtained in an Instron tensile testing machine at a strain rate of $10^{-3} \mathrm{~s}^{-1}$ at room temperature. Composites with commercial purity aluminium and AA6061 with SiC particulates with an average diameter of $14.5 \mu \mathrm{m}$ were fabricated by the powder metallurgy route. Aluminium alloy powder was blended with $15 \%$ and $20 \%$ by volume of SiC particles. The blend was degassed and compacted using cold isostatic pressing. The billets were vacuum hot pressed and extruded. Tensile test samples with $5 \mathrm{~mm}$ gauge diameter and $25 \mathrm{~mm}$ gauge length were machined from these composites and tested for mechanical properties. 
Table 1. Chemical composition of various aluminium alloys used in the present work.

\begin{tabular}{|c|c|c|c|c|c|c|c|c|c|c|c|}
\hline $\begin{array}{l}\text { Sl. } \\
\text { no. }\end{array}$ & Alloy & $\begin{array}{l}\mathrm{Cu} \\
(\%)\end{array}$ & $\begin{array}{l}\mathrm{Mg} \\
(\%)\end{array}$ & $\begin{array}{l}\mathrm{Mn} \\
(\%)\end{array}$ & $\begin{array}{l}\mathrm{Si} \\
(\%)\end{array}$ & $\begin{array}{l}\mathrm{Fe} \\
(\%)\end{array}$ & $\begin{array}{l}\mathrm{Ni} \\
(\%)\end{array}$ & $\begin{array}{l}\mathrm{Cr} \\
(\%)\end{array}$ & $\begin{array}{l}\mathrm{Zn} \\
(\%)\end{array}$ & $\begin{array}{c}\mathrm{Ti} \\
(\%)\end{array}$ & $\begin{array}{c}\mathrm{Al} \\
(\%)\end{array}$ \\
\hline 1. & AA6061 & $0 \cdot 4$ & $1 \cdot 2$ & $0 \cdot 15$ & $0 \cdot 8$ & $0 \cdot 7$ & - & $0 \cdot 35$ & $0 \cdot 25$ & $0 \cdot 15$ & Bal \\
\hline 2. & AA7075 & $2 \cdot 0$ & $2 \cdot 9$ & 0.03 & $0 \cdot 4$ & $0 \cdot 5$ & - & $0 \cdot 4$ & $6 \cdot 1$ & $0 \cdot 2$ & $\mathrm{Bal}$ \\
\hline 3. & AA2014 & $5 \cdot 0$ & $0 \cdot 8$ & $1 \cdot 2$ & $1 \cdot 2$ & $0 \cdot 7$ & - & $0 \cdot 1$ & $0 \cdot 25$ & $0 \cdot 15$ & Bal \\
\hline 4. & AA2024 & 4.9 & $1 \cdot 8$ & $0 \cdot 9$ & $0 \cdot 5$ & $0 \cdot 5$ & - & $0 \cdot 1$ & $0 \cdot 25$ & - & Bal \\
\hline 5. & AA7010 & $2 \cdot 0$ & $2 \cdot 7$ & $0 \cdot 3$ & $0 \cdot 10$ & $0 \cdot 15$ & - & $0 \cdot 05$ & $6 \cdot 7$ & - & Bal \\
\hline 6. & $\begin{array}{l}\text { Commercial } \\
\text { purity Al }\end{array}$ & $0 \cdot 2$ & $0 \cdot 05$ & $0 \cdot 05$ & $1 \cdot 0$ & $0 \cdot 4$ & - & - & $0 \cdot 1$ & - & Bal \\
\hline
\end{tabular}

\section{Results and discussion}

The generated engineering stress-strain curves were converted into true stress-true strain curves. Figure 1 shows the true stress-true strain curves for different aluminium alloys viz. AA6061, AA2024, AA7010, AA2014, AA7075 and commercial purity aluminium. It is observed that commercial purity aluminium has the lowest yield strength and AA7010 has the highest yield strength. It is assumed that the non-linear part of the curve followed ZenerHollomon relationship (Meyers and Chawla 1999) i.e.

$$
\sigma=\kappa \varepsilon_{\rho}^{n}
$$

where, $\sigma$ is the true stress, $\varepsilon_{\rho}$ the true plastic strain, $n$ the strain hardening exponent and $\kappa$ a constant.

From the slope of the $\log$ (true stress) vs $\log$ (true strain) plots, the strain hardening exponents were calculated. Table 2 shows the strain hardening exponents for various alloys.

Differentiating (1) w.r.t. $\varepsilon$

$$
\begin{aligned}
& \frac{\mathrm{d} \sigma}{\mathrm{d} \varepsilon}=\kappa n \varepsilon^{n-1}=\kappa \frac{n \varepsilon^{n}}{\varepsilon}, \\
& \frac{\mathrm{d} \sigma}{\mathrm{d} \varepsilon}=\frac{n \sigma}{\varepsilon} .
\end{aligned}
$$

From the above relationship, the work hardening rate $\mathrm{d} \sigma / \mathrm{d} \varepsilon$ was calculated at different strain values. Figure 2 shows the curve of $\mathrm{d} \sigma / \mathrm{d} \varepsilon$ vs true strain $\left(\varepsilon_{\rho}\right)$ for various alloys. It is seen that the work hardening curve is the lowest for commercial purity aluminium and highest for AA7075 alloy. Work hardening curves are placed in increasing order viz. commercial purity aluminium, 6061, 2024, 7010, 2014 and 7075.

Table 3 shows the mechanical properties of SiC/Al metal matrix composites with various aluminium alloy matrices. The objective of the exercise is to correlate the results of table 3 with those of figure 2 .

It is seen from table 3 that the maximum yield strength increment occurs for commercial purity aluminium (300\%),

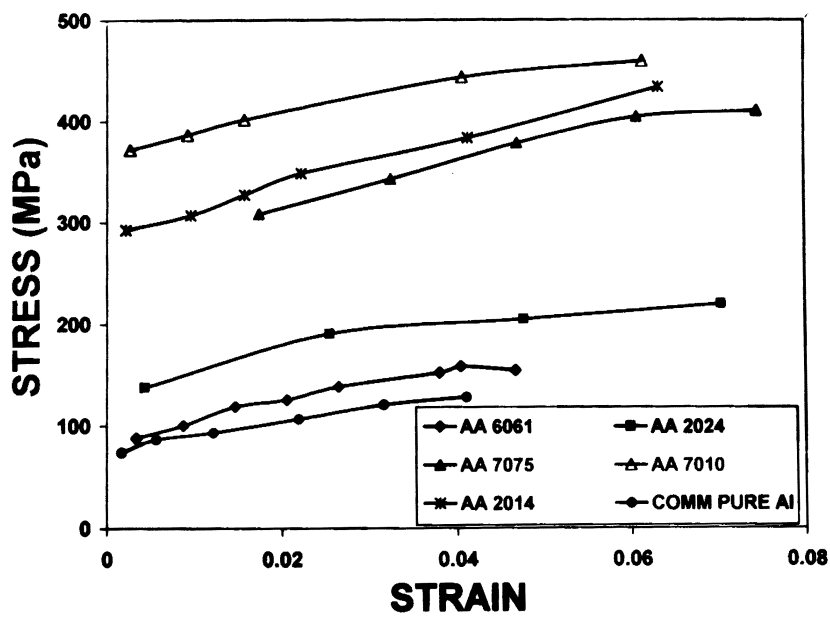

Figure 1. True stress-true strain curves for different aluminium alloys.

Table 2. Strain hardening exponents in various alloys.

\begin{tabular}{llc}
\hline $\begin{array}{l}\text { Sl. } \\
\text { no. }\end{array}$ & Alloy & $\begin{array}{c}\text { Strain hardening } \\
\text { exponent }\end{array}$ \\
\hline 1. & AA6061 & $0 \cdot 23$ \\
2. & AA2024 & $0 \cdot 16$ \\
3. & AA7075 & $0 \cdot 21$ \\
4. & AA7010 & $0 \cdot 07$ \\
5. & AA2014 & $0 \cdot 12$ \\
6. & Commercial & $0 \cdot 17$ \\
& purity Al & \\
\hline
\end{tabular}

followed by $6061(40 \%), 2024(40 \%), 7010(19 \%)$ and $7075(1.62 \%)$.

The model of Arsenault and Shi (1986) predicts an increment in dislocation density ' $\rho$ ' due to CTE mismatch between reinforcement and matrix by prismatic punching of dislocations around reinforcement particles.

$$
\Delta \rho=\frac{\Delta \alpha \Delta T N A}{b}
$$

where $\Delta \alpha$ is the CTE mismatch, $\Delta T$ the temperature difference, $N$ the number of particles, $A$ the total surface area 
Table 3. Mechanical properties of metal-matrix composites.

\begin{tabular}{|c|c|c|c|c|c|c|c|c|}
\hline $\begin{array}{l}\text { S1. } \\
\text { no. }\end{array}$ & $\begin{array}{l}\text { Matrix } \\
\text { alloy }\end{array}$ & $\begin{array}{l}\text { Volume } \\
\text { fraction } \\
\quad(\%)\end{array}$ & $\begin{array}{l}\text { Composite } \\
\text { Y.S. } \\
\text { (Mpa) }\end{array}$ & $\begin{array}{l}\text { Composite } \\
\text { UTS } \\
\text { (Mpa) }\end{array}$ & $\begin{array}{l}\text { Y.S. of unre- } \\
\text { inforced ma- } \\
\text { trix } \\
(\mathrm{Mpa})\end{array}$ & $\begin{array}{l}\text { UTS of } \\
\text { unreinforced } \\
\text { matrix } \\
\text { (Mpa) }\end{array}$ & $\frac{\left(\mathrm{YS}_{\text {comp }}-\mathrm{YS}_{\text {matrix }}\right)}{\mathrm{YS}_{\text {matrix }}} \times 100$ & Reference \\
\hline 1. & AA6061 & $15 \mathrm{SiC}_{\mathrm{p}} \mathrm{T} 6$ & 388 & 396 & 266 & 307 & $45 \cdot 86$ & Our results \\
\hline 2. & AA6061 & $20 \mathrm{SiC}_{\mathrm{p}} \mathrm{T} 6$ & 370 & 410 & 266 & 307 & $39 \cdot 09$ & Our results \\
\hline 3. & AA2024 & $5 \mathrm{SiC}_{\mathrm{w}} \mathrm{T} 4$ & 476 & 648 & 341 & 502 & $39 \cdot 58$ & $\begin{array}{l}\text { Clyne and } \\
\text { Withers (1993) }\end{array}$ \\
\hline 4. & AA7010 & $15 \mathrm{SiC}_{\mathrm{p}} \mathrm{T} 6$ & 560 & 582 & 470 & 530 & $19 \cdot 14$ & Nair et al (1985) \\
\hline 5. & AA7075 & $18 \mathrm{SiC}_{\mathrm{p}}$ & 437 & 617 & 430 & 500 & $1 \cdot 62$ & Nair et al (1985) \\
\hline 6. & $\begin{array}{l}\text { Commercial } \\
\text { purity Al }\end{array}$ & $15 \mathrm{SiC}_{\mathrm{p}}$ & 120 & 156 & 29 & 75 & $313 \cdot 00$ & Our results \\
\hline
\end{tabular}

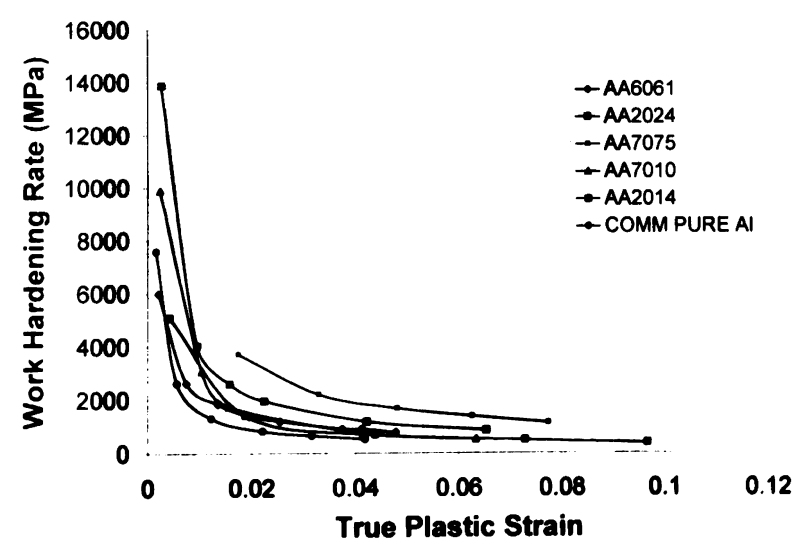

Figure 2. Work hardening rate $\mathrm{d} \sigma / \mathrm{d} \varepsilon$ vs true strain for different aluminium alloys.

of each particle, $b$ the burger's vector and $\Delta \rho$ the increment in dislocation density.

The increments in matrix yield strength can be predicted by (Clyne and Withers 1993)

$$
\Delta \sigma \cong G b \sqrt{\Delta \rho},
$$

$G$ being shear modulus, $\Delta \rho$ the dislocation density, $\Delta \sigma$ the increment in yield strength.

It can be seen that while the work hardening rate in commercial purity aluminium is very low (figure 2 ), the strength increment is the highest (table 3) amongst the alloys being compared. This can be understood by the Arsenault and Shi model wherein the prismatic punching of dislocations becomes predominant in this system.

This relationship of decreasing work hardening rate associated with increasing prismatic punching of disloca- tions in the order 7075, 2014, 7010, 2024, 6061 and commercial purity aluminium can be noted.

Thus it is seen that a rationale can be proposed based on the work hardening rate $(\mathrm{d} \sigma / \mathrm{d} \varepsilon)$ to explain the increment in yield strength of the metal-matrix composite with various aluminium alloy matrices. Therefore the work hardening characteristics of the alloy have a direct influence on the strength of discontinuous metal-matrix composites.

\section{Conclusions}

From the study, it is concluded that lower the work hardening rate, higher is the strengthening and vice versa in particulate metal-matrix composites.

\section{Acknowledgements}

The authors would like to thank the management of Hindustan Aeronautics Ltd., for supporting this work and Dr Radhakrishna Bhat, DMRL, for fruitful discussion.

\section{References}

Arsenault R J and Fisher R M 1983 Scr. Metall. 1767

Arsenault R J and Shi N 1986 Mater. Sci. Eng. 81175

Arsenault R J, Wang L and Feng C K 1991 Acta Metall. 3947

Clyne T W and Withers P J 1993 An introduction to metal matrix composites (UK: Cambridge University Press) p. 7

Marcus H L 1984 Microscopic study of the influence on interface bonding, Report no. UTSCMSE-84-1, University of Texas

Meyers M A and Chawla K K 1999 Mechanical behaviour of materials (USA: Prentice Hall Inc.) p. 116

Nair S V, Tien J K and Bates R C 1985 Int. Mater. Rev. 30275

Vogelsang M, Fisher R M and Arsenault R J 1986 Met. Trans. A17 379

Webster D 1982 Met. Trans. A13 1511 